\title{
Liberação específica de fármacos no cólon por via oral. II - Tipos de sistemas utilizados
}

\author{
Ana Cristina Freire', Fridrun Podczeck², João Sousa', Francisco Veiga ${ }^{1 *}$ \\ ${ }^{1}$ Faculdade de Farmácia, Universidade de Coimbra, Coimbra, Portugal,', Faculdade de Farmácia, Universidade de \\ Sunderland, Reino Unido
}

*Correspondência:

F. Veiga

Faculdade de Farmácia de Coimbra

Rua do Norte, 3000

Coimbra - Portugal

E-mail: fveiga@ci.uc.pt
Dois tipos de abordagens podem ser utilizadas para liberar fármacos no cólon: liberação retardada ou liberação específica no cólon. O primeiro caso diz respeito a formulações concebidas de forma a prolongar a dissolução do fármaco e a sua absorção, até que a formulação chegue ao cólon. Esta estratégia demonstra falta de especificidade quando comparada com outras que se baseiam nas características particulares do cólon. A liberação específica no cólon explora as suas propriedades como o $\mathrm{pH}$, atividade enzimática e pressão intraluminal. No geral, o sistema ideal pode ser obtido com a utilização de peletes, que como é sabido possuem maior previsibilidade no seu esvaziamento gástrico e maior tempo de residência no cólon, ou sistemas revestidos com um design simples. Teoricamente, os sistemas baseados na atividade enzimática, e, sobretudo, os que são constituídos por polissacarídeos, são mais específicos e possuem baixa toxicidade. No entanto, qualquer outro sistema pode ser eficaz na liberação específica de fármacos no cólon. Na realidade, alguns sistemas tempo e pH dependentes comercializados, têm mostrado beneficios no tratamento da doença inflamatória do intestino, apesar da sua baixa especificidade. As investigações neste campo, devem ser conduzidas de forma a identificar a estratégia apropriada, que permita a liberação especifica do fármaco de maneira segura, efetiva, pouco dispendiosa e com a mínima flutuação em termos de liberação de fármacos no local alvo.

\section{INTRODUÇÃO}

Na primeira parte desta revisão o cólon foi descrito como local de liberação de fármacos, dando especial atenção a aspetos fundamentais para o desenvolvimento de

\section{Unitermos}

- Liberação específica no cólon

- Sistemas tempo-dependentes

- Sistemas pH-dependentes

- Sistemas baseados na microflora

- Sistemas baseados na pressão intraluminal sistemas de liberação específica de fármacos no cólon tais como: $\mathrm{pH}$, trânsito gastrointestinal, microflora intestinal, patologias e capacidade do cólon para absorver fármacos. Ficou evidente que a concepção de sistemas de liberação específica de fármacos no cólon não é fácil uma vez que 
estes devem evitar as condições adversas do trato gastrointestinal superior (pH ácido do estômago e atividade enzimática intensa no intestino delgado) e atingir regiões específicas do cólon, sendo o cego e a região do cólon ascendente, as zonas mais adequadas para a liberação (Peeters, Kinget, 1993; Ashford, Fell, 1994).

Do ponto de vista tecnológico, formas farmacêuticas como cápsulas, comprimidos ou peletes, revestidos ou matriciais têm constituído a base destes sistemas.

No entanto, para se obter especificidade no local de liberação do princípio ativo, inerente a estas formas farmacêuticas encontra-se o mecanismo responsável pela liberação. Neste contexto, dois tipos diferentes de abordagens podem ser utilizados para promover a liberação específica de fármacos no cólon: liberação específica e liberação retardada (Quadros et al., 1995). A primeira abordagem é mais específica dado que explora diferenças fisiológicas entre o cólon e as restantes regiões do trato gastrointestinal tais como $\mathrm{pH}$, microflora e pressão intraluminal do cólon.

No segundo caso, encontramos os sistemas tempodependentes que, embora dotados de baixa especificidade, têm sido a base de alguns produtos comercializados para o tratamento da doença inflamatória do intestino.

O objetivo da revisão é descrever, avaliar e comparar a efetividade dos sistemas usados na liberação específica de fármacos no cólon.

\section{SISTEMAS TEMPO-DEPENDENTES}

Algumas formulações de liberação controlada podem ser concebidas de forma a prolongar a dissolução do fármaco e, consequentemente, a sua absorção. Estas formulações, apesar de menos sofisticadas, são a base de um produto comercializado para o tratamento da doença inflamatória do intestino. É o caso do Pentasa ${ }^{\circledR}$, que consiste em comprimidos resultantes da compressão de microgrânulos de ácido 5-aminosalicílico revestidos por etilcelulose. Uma vez em contato com os fluídos do trato gastrointestinal, o comprimido desagrega-se e libera os microgrânulos revestidos. Forma-se um gel em redor de cada microgrânulo que vai intumescendo, com diferentes graus em função da concentração de etilcelulose usada. Este mecanismo torna possível um tempo de latência, que será tanto maior, quanto mais espessa a camada de etilcelulose empregue, permitindo assim, controlar o local de liberação do princípio ativo. A liberação do ácido 5-aminosalicílico faz-se mediante um processo de erosão e difusão através da camada de gel. Contudo, esta estratégia parece ser dotada de pouca especificidade. Num estudo de $\gamma$-cintilografia realizado em 9 voluntários humanos, a liberação do ácido 5aminosalicílico iniciou-se no estômago ou intestino delgado sendo, normalmente, detectável 30 a 60 minutos após a ingestão do Pentasa ${ }^{\circledR}$ (Wilding, 1995).

Para contornar esta limitação, outro tipo de sistemas tempo-dependentes têm sido propostos. Estes sistemas eliminam a variabilidade associada ao tempo de esvaziamento gástrico e exploram o tempo de trânsito relativamente constante ao longo do intestino delgado. Devem ser estáveis no ambiente ácido do estômago e, após a passagem ao intestino, acionar o mecanismo responsável pelo tempo pré-determinado de latência (Gazzaniga et al., 1995), o qual deve simular a permanência do sistema no intestino delgado e posteriormente deve liberar o princípio ativo. Caso seja possível obter um tempo de latência reprodutível, esta estratégia pode ser bastante promissora (Leopold, 1999).

Sistemas tempo-dependentes com estas características foram desenvolvidos por Gazzaniga (Gazzaniga et al., 1994, 1995). Um desses sistemas apresentava a seguinte configuração: i) uma camada externa gastroresistente; ii) uma camada intermediária formada por um polímero hidrofílico (HPMC de elevada viscosidade), com capacidade de intumescer em contato com a água, responsável pelo tempo de latência e iii) um núcleo onde se encontra o fármaco. Pode estar presente um camada entérica adicional, entre o núcleo e a camada intermediária que, sendo de natureza gastroresistente, assegura que a liberação do fármaco não ocorra em valores de $\mathrm{pH}$ ácidos, no caso da camada hidrofílica se dissolver prematuramente. Ao chegar ao duodeno, a camada externa dissolve-se e o polímero entra em contato com os fluídos intestinais formando um gel que retarda o contato do fármaco com o meio de dissolução. A liberação do fármaco faz-se por um processo de intumescimento e erosão da camada hidrofílica, pelo que está dependente da espessura da mesma. Esta formulação foi testada in vivo, e revelou um período de latência entre 5 e 10 horas, o que sugere boas características para liberação de componentes ativos no cólon.

A sua principal limitação diz respeito à utilização de HPMC de elevada viscosidade no decurso do processo de revestimento. Para atomizar dispersões aquosas destes polímeros, é necessário usar baixas concentrações, o que pressupõem tempos de processamento muito elevados. Este problema pode ser, em parte, solucionado com o recurso a dispersões hidro-alcoólicas de HPMC de elevada viscosidade, se bem que a utilização de solventes orgânicos constitui um problema adicional.

No decurso destas conclusões, os mesmos autores propuseram o uso da HPMC de baixa viscosidade, como agente retardante. No entanto, para obter o mesmo tempo de latência, é necessário aumentar a espessura da camada de HPMC de baixa viscosidade. 
O sistema Pulsincap ${ }^{\circledR}$ (McNeil, Stevens, 1990) (Figura 1) baseia-se no mesmo príncipio das formulações descritas atrás. Consiste numa cápsula que possui uma parte insolúvel e outra revestida por um polímero entérico. A secção gastroresistente dissolve-se à entrada do intestino delgado expondo um hidrogel, que em contacto com a água vai intumescer, e ao fim de algum tempo destaca-se promovendo a liberação do fármaco. Esta liberação é controlada pelo grau de intumescimento do hidrogel, que por sua vez, é independente do $\mathrm{pH}$, e que deve decorrer durante 3 a 4 horas, isto é, o tempo necessário para que este sistema atinja o cólon. Um estudo de ${ }^{3}$-cintilografia (Gilchrist et al., 1995) provou a eficácia deste sistema demonstrando que a liberação do fármaco tem lugar na válvula ileocecal ou no cólon ascendente.

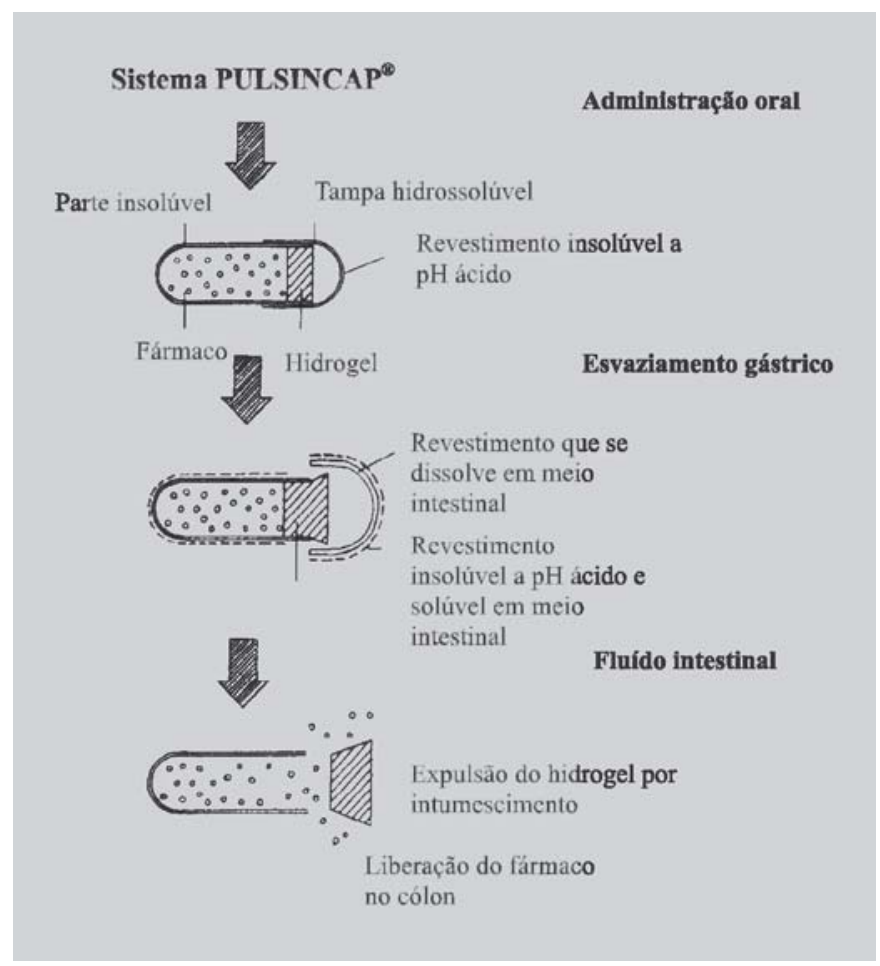

FIGURA 1 - Esquema do sistema Pulsincap ${ }^{\circledR}$. Adaptado de Mcneil e Stevens, 1990.

O sistema Time Clock ${ }^{\circledR}$ (McNeil, Stevens, 1990) é outra formulação tempo-dependente que consiste no revestimento de um núcleo com uma mistura de polímeros hidrofóbicos (ceras de carnaúba e de abelha) e um tensoativo (Tween 80), ao qual se adiciona um polímero hidrofílico para melhorar a sua adesividade ao núcleo. O objetivo é a liberação rápida e completa do princípio ativo após um tempo prédeterminado de latência, a qual depende da espessura da camada hidrofóbica e é independente do $\mathrm{pH}$ e o do estado de nutrição (Pozzi et al., 1994). Os testes realizados em voluntários humanos (Wilding et al., 1994), provaram a efetividade deste sistema, ao demonstarem que a liberação do fármaco ocorre cerca de 10 horas pós-dose e 7,5 horas após o esvaziamento gástrico, o qual é independente do $\mathrm{pH}$, tempo de retenção gástrica e estado de nutrição. O local anatômico da liberação varia entre o cego e o cólon descendente, e o tempo necessário para que ocorra a desintegração completa é da ordem dos 45-60 minutos. Em estudo posterior (Steed et al., 1997) foi avaliado com sucesso o potencial deste sistema para liberar especificamente o ácido 5-aminosalicílico no cólon proximal de oito voluntários humanos.

Algumas formulações baseiam-se na tecnologia das bombas osmóticas para promover a liberação de princípios ativos no cólon. É o caso do sistema OROS-CT ${ }^{\circledR}$ (Figura 2) que pode ser formado por uma única unidade osmótica ou por um conjunto de 5 a 6 unidades que se encontram no interior de uma cápsula de gelatina (Tweeuwes et al., 1993). Este sistema é composto por um compartimento osmótico e por um compartimento que contém o princípio ativo, rodeados por uma membrana semipermeável. Existe um orifício na membrana semipermeável adjacente ao compartimento que encerra o fármaco. Este dispositivo é rodeado por uma membrana entérica. Uma vez em contacto com os fluídos do intestino delgado, a cobertura entérica dissolvese, promovendo a entrada de água no sistema. Como consequência, o compartimento osmótico intumesce e força a saída do fármaco através do orifício, a uma velocidade controlada pela velocidade de transporte da água através da membrana semipermeável. A liberação de fármacos a partir deste sistemas é independente de fatores fisiológicos do trato gastrointestinal. Ao modificar alguns fatores de formulação, como a solubilidade e pressão osmótica dos componentes do núcleo, o tamanho do orifício e a natureza da membrana que controla a entrada de água no sistema podem obter-se diferentes tempos de latência (Verma et al., 2002). O OROS-CT ${ }^{\circledR}$ foi concebido para provocar um atraso pósgástrico de 3 a 4 horas, evitando que a liberação ocorra no intestino delgado (Tweeuwes et al., 1993).

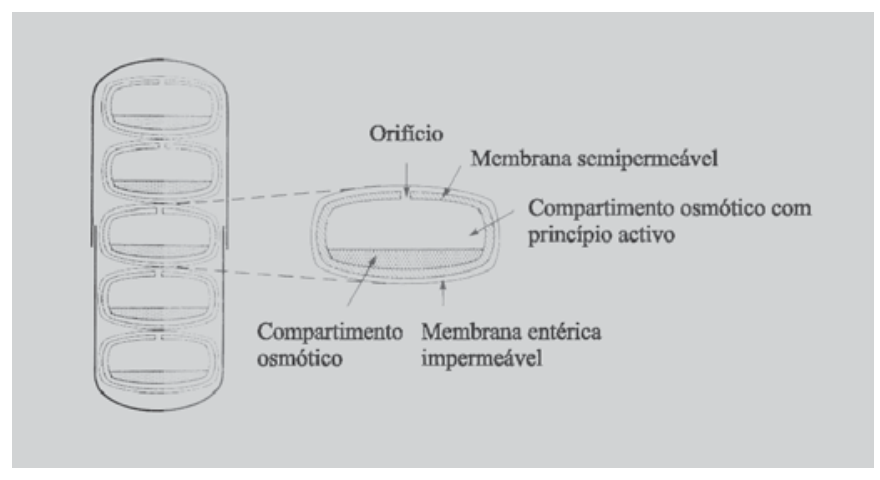

FIGURA 2 - Esquema de um sistema de liberação colônica OROS-CT ${ }^{\circledR}$. Adaptado de Theeuwes et al., 1993. 


\section{SISTEMAS PH-DEPENDENTES}

Os sistemas $\mathrm{pH}$-dependentes exploram as variações de $\mathrm{pH}$ ao longo do trato gastrointestinal para liberar seletivamente fármacos no cólon. Baseiam-se, geralmente, no revestimento de comprimidos, peletes e cápsulas com polímeros insolúveis a $\mathrm{pH}$ ácido e solúveis a $\mathrm{pH}$ neutro ou ligeiramente alcalino. Estes polímeros devem ser capazes de prevenir a liberação do componente ativo no estômago e intestino delgado proximal e promovê-la no íleo terminal ou cólon proximal.

Os copolímeros derivados do ácido metacrílico e metilmetacrílico, comercializados como Eudragit ${ }^{\circledR}$, satisfazem estas condições, pelo que são bastante utilizados na concepção de sistemas pH-dependentes. Além disso, os revestimentos constituídos por estes polímeros, podem ser aplicados nas várias formas farmacêuticas sólidas recorrendo a todos os equipamentos convencionais utilizados pela indústria farmacêutica. A liberação do fármaco a partir de formas farmacêuticas revestidas por Eudragit ${ }^{\circledR}$ é dependente do $\mathrm{pH}$ do meio de dissolução e da espessura do revestimento. Alguns autores sugerem quantidades de polímero da ordem dos $10-12 \%$ em relação ao peso total do comprimido para obter revestimentos resistentes ao $\mathrm{pH}$ ácido do estômago e capazes de retardar a liberação até que a forma farmacêutica atinja o cólon (Healey, 1989).

Entre os vários tipos (Figura 3) os polímeros Eudragit ${ }^{\mathbb{R}}$ $\mathrm{S}$ e L que se dissolvem, respectivamente, para valores de $\mathrm{pH}$ superiores a 7 e 6 são os mais empregados. A diferença de solubilidade em meio aquoso destes copolímeros depende de relação existente entre os grupos carboxílicos livres e esterificados que é de 1:2 para o Eudragit ${ }^{\circledR} \mathrm{S}$ e de 1:1 para o Eudragit ${ }^{\mathbb{}}$ L. A utilização de Eudragit ${ }^{\mathbb{R}} \mathrm{S}$ no âmbito da liberação específica de fármacos no cólon foi pela primeira vez referida em 1982 (Dew et al., 1982).

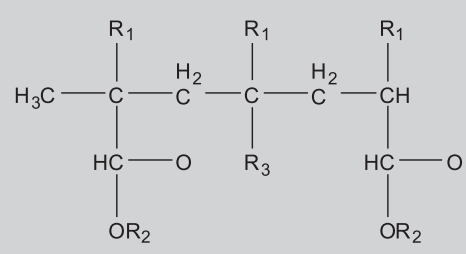

$\mathrm{R}_{1}=-\mathrm{CH}_{3}, \mathrm{R}_{2}=-\mathrm{CH}_{3}$ e $\mathrm{R}_{3}=-\mathrm{COOH}$ (Eudragit L e S)

$\mathrm{R}_{1}=-\mathrm{CH}_{3}, \mathrm{R}_{2}=-\mathrm{CH}_{2} \mathrm{CH}_{3}$ e $\mathrm{R}_{3}=-\mathrm{COOH}$ (Eudragit L100-55 e L30D-55)

$\mathrm{R}_{1}=-\mathrm{CH}_{3}, \mathrm{R}_{2}=-\mathrm{CH}_{3}$ e $\mathrm{R}_{3}=-\mathrm{COOCH}_{3}\left(\right.$ Eudragit $\left.{ }^{\circledR} \mathrm{NE} 30 \mathrm{D}\right)$

$\mathrm{R}_{1}=-\mathrm{CH}_{3}, \mathrm{R}_{2}=-\mathrm{CH}_{3}$ e $\mathrm{R}_{3}=-\mathrm{COOCH}_{2}^{+} \mathrm{CH}_{2} \mathrm{~N}\left(\mathrm{CH}_{3}\right)_{3} \mathrm{Cl}^{-}\left(\right.$Eudragit $\left.{ }^{\circledR} \mathrm{NE} 30 \mathrm{D}\right)$

FIGURA 3 - Estrutura química de vários tipos de Eudragit ${ }^{\circledR}$.
Desde então, os sistemas que se baseiam no revestimento com estes polímeros compostos têm sido amplamente explorados sobretudo no tratamento da doença inflamatória do cólon.

Nos últimos anos, ligeiras modificações aos revestimentos anteriores têm sido propostas. Peteers e Kinget (1993) avaliaram o efeito da metilação parcial dos grupos carboxílicos livres do polímero Eudragit ${ }^{\circledR} \mathrm{S}$ com o intuito de obter um perfil de dissolução mais favorável às condições de $\mathrm{pH}$ do cólon. Os resultados demonstraram uma dissolução em água a valores de $\mathrm{pH}$ superiores, o que se correlacionou in vivo com melhores características de dissolução no pH do cólon.

A utilidade de polímeros lipofílicos obtidos a partir da substituição de um derivado metacrílico por ácidos gordos, na preparação de misturas físicas pH-dependentes destinadas à liberação específica do ibuprofeno foi investigada (Luppi et al., 2003). Estas misturas foram avaliadas in vitro, concluindo-se que algumas delas seriam interessantes na liberação específica no cólon, por retardarem a liberação no trato gastrointestinal superior e promover uma elevada biodisponibilidade do ibuprofeno no cólon. Outra possibilidade consiste na utilização de misturas de polímeros (Eudragit ${ }^{\circledR}$ L100-55 e Eudragit ${ }^{\circledR}$ S100) com diferentes solubilidades, no revestimento de comprimidos, de modo a obter perfis de dissolução do revestimento menos susceptíveis a variações interindividuais de $\mathrm{pH}$ (Khan, Prebeg, Kurjakovic, 1999).

Apesar da sua ampla utilização e investigação, a especificidade destas formulações $\mathrm{pH}$-dependentes suscitou, desde sempre, algumas dúvidas na medida em que diferenças mínimas de valores de $\mathrm{pH}$ ao longo do intestino, aliada à variabilidade a que estão sujeitas as condições fisiológicas no trato gastrointestinal, não podem constituir um mecanismo efetivo para deflagar a liberação específica de fármacos.

Ashford et al. (1993a, b) avaliaram a eficácia de comprimidos de ácido salicílico revestidos por Eudragit ${ }^{\circledR}$ $\mathrm{S}$ e demonstraram que além do $\mathrm{pH}$ do meio a liberação é dependente da espessura do revestimento. A retenção por longos períodos na válvula ileocecal e um tempo de trânsito rápido, provaram a ineficácia dos comprimidos como formas farmacêuticas concebidas sob a forma de sistemas de liberação específica no cólon. O tempo de chegada ao cólon e de desagregação revelaram-se altamente variáveis sendo que a dissolução pode ou não ocorrer, prematuramente, no duodeno.

Para contornar o problema de falta de reprodutiblidade e especificidade no local de liberação resultante da variabilidade nos tempos de trânsito gastrointestinal dos comprimi- 
dos, a utilização de sistemas multiparticulados tem sido equacionada em vários estudos (Rudolph et al., 2001, Gupta et al., 2001; Lamprecht et al., 2003; Lamprecht et al., 2004). A comparação, in vivo, do trânsito gastrointestinal de peletes e comprimidos, bem como do local de liberação do príncipio ativo a partir destas formulações tem mostrado resultados ligeiramente favoráveis aos peletes. Contudo, estes estudos recentes são realizados em indíviduos saudáveis pelo que a relevância destes resultados carece de uma investigação mais profunda (Brunner et al., 2003; Wilding et al., 2003).

Para além desta limitação, todos os sistemas $\mathrm{pH}$-dependentes descritos têm em comum o fato de se basearem num aumento do valor de $\mathrm{pH}$ na passagem do íleo para o cólon proximal. No entanto, tal como foi discutido na primeira parte desta revisão, este fato parece não estar totalmente correto nem em indíviduos saudáveis nem em indíduos com patologias colônicas aos quais se destinam estes sistemas. $\mathrm{O}$ fato de alguns estudos sugerirem que o $\mathrm{pH}$ luminal do cólon durante ataques agudos da doença inflamatória do intestino cai para valores na ordem dos 2,3 e 4,7, constituíu o ponto de partida para a preparação de comprimidos de dexametasona revestidos por um polímero ácidosolúvel (Leopold, Eikeler, 2000). O sistema é formado por 3 camadas: uma camada externa gastroresistente de HPMC, uma camada intermediária de HPC e uma camada interna de Eudragit ${ }^{\circledR} \mathrm{E}$ ou de polivinilacetal dietilaminoacetato (AEA) (Figura 4). A presença de uma camada intermediária deve-se ao fato de o HPC ser um polímero inerte que inibe fenomenos de interação entre as duas restantes camadas. Após a dissolução do revestimento gastroresistente, a camada interna de Eudragit ${ }^{\mathbb{B}} \mathrm{E}$ ou AEA promove a libera-

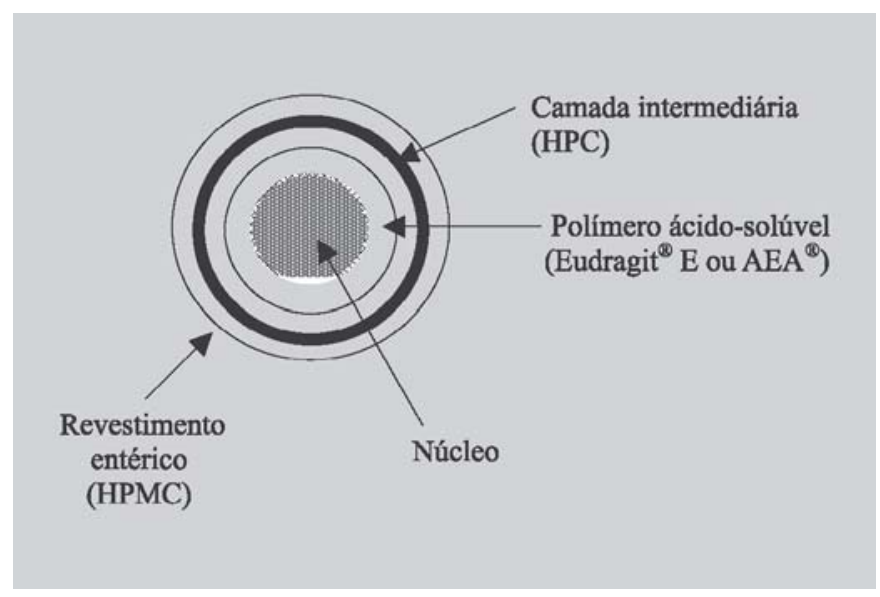

FIGURA 4 - Esquema de um sistema de liberação específica de fármacos no cólon destinado a liberar o princípio ativo quando o $\mathrm{pH}$ do cólon se torna ácido durante ataques agudos da doença inflamatória do intestino. Adaptado de Leopold e Eikeler, 2000. ção da dexametasona nos locais de inflamação onde o pH é presumivelmente ácido, e no qual estes polímeros se dissolvem. Estudos in vitro, revelaram que os perfis de dissolução destes sistemas e, particularmente, dos polímeros que formam a camada interna, se adequam à liberação específica de fármacos sob as condições ácidas no cólon de pacientes com diagnóstico de doença inflamatória do intestino.

Para além das formulações revestidas, a concepção de matrizes pH-dependentes é, igualmente, uma realidade na tentativa de promover uma liberação específica no cólon.

Krogars et al. (2000) utilizaram Eudragit ${ }^{\circledR} \mathrm{S}$ para formular peletes matriciais constituídos por ibuprofeno $\mathrm{e}$ ácido cítrico e testaram a formulação in vitro. A investigação revelou a incapacidade dos sistemas matriciais para liberar especificamente fármacos no cólon. No entanto, verificaram que a redução do $\mathrm{pH}$ causada pela presença do ácido cítrico retardou a dissolução do polímero entérico e consequentemente a liberação do ibuprofeno em soluções tamponadas a $\mathrm{pH}$ 7,4 foi retardada em 15 minutos.

Outros autores (Nykänen et al., 1999, 2001) têm investigado o uso de ácidos orgânicos em grânulos matricias entéricos destinados a liberar um agente terapêutico no cólon. Apesar da observação de que um ácido orgânico pode atrasar a liberação in vitro de um fármaco, nenhuma evidência foi encontrada in vivo.

Os ácidos orgânicos foram utilizados por Ishibashi e colaboradores (1998) no desenvolvimento de uma cápsula designada de $\mathrm{CTDC}^{\circledR}$ (Figura 5). Esta cápsula possui características únicas, na medida em que alia propriedades tempo e $\mathrm{pH}$-dependentes. A principal característica técnica do sistema consiste na presença de um ácido orgânico juntamente com o princípio ativo numa cápsula revestida por 3 camadas constituídas por um polímero ácido-solúvel, um polímero solúvel em água e por um polímero entérico. O polímero entérico constitui o revestimento



FIGURA 5 - Esquema do sistema $\mathrm{CTDC}^{\circledR}$. Adaptado de Ishibashi et al.,1998. 
mais externo e dissolve-se após o esvaziamento gástrico, tal como a camada intermediária. A cápsula fica reduzida ao revestimento por um polímero ácido-solúvel que se dissolve logo que o $\mathrm{pH}$ do micro-ambiente no seu interior diminui, devido à dissolução do ácido orgânico. Após a dissolução deste polímero, o fármaco é rapidamente liberado em função da espessura da camada interna. Aliando a resistência ao $\mathrm{pH}$ ácido com a espessura da camada interna, pode-se conseguir retardar a liberação por períodos de 3 a 4 horas e, assim, obter um efetivo sistema de liberação específica no cólon. O comportamento deste sistema foi avaliado em cães (Ishibashi et al., 1999), demonstrando ter potencial para liberar fármacos no cólon.

O sistema mais complexo de todos os que foram descritos até ao momento é o sistema $\mathrm{CODES}^{\circledR}$. A sua finalidade é aliar as propriedades tempo e $\mathrm{pH}$-dependentes à especificidade da meolização pela microflora do cólon, eliminando, assim, a variabilidade que é atribuída aos primeiros sistemas (Watanabe et al., 1998). Este sistema consiste num núcleo formado por um fármaco e lactulose, revestido internamente por um polímero ácido-solúvel e no exterior por um polímero entérico. Assim que o sistema abandona o estômago, o revestimento entérico dissolve-se, expondo a segunda camada formada por Eudragit ${ }^{\mathbb{B}}$ E. Este polímero dissolve-se em $\mathrm{pH}$ inferior a 5, pelo que não se dissolverá no conteúdo intestinal. A liberação do fármaco baseia-se na conversão da lactulose pela microflora do cólon em ácidos orgânicos, promovendo um abaixamento do $\mathrm{pH}$ envolvente que permitirá a dissolução do revestimento.

Um sistema CODES ${ }^{\circledR}$ placebo (Takemura et al., 2000) foi administrado a 8 voluntários humanos e o seu comportamento avaliado através da técnica de ${ }^{3}$ cintilografia. A desintegração do sistema ocorreu no cólon e o seu trânsito mostrou-se independente do estado de nutrição dos indíviduos em estudo. No entanto, esta investigação revelou um aspecto menos positivo: a sua desintegração completa demorou cerca de 60 minutos, o que corresponde ao tempo necessário para que ocorra suficiente produção de ácido e consequente dissolução do polímero ácido-solúvel.

\section{SISTEMAS BASEADOS NA MICROFLORA DO CÓLON}

Como já foi referido, o cólon é colonizado por um elevado número de bactérias que lhe conferem uma capacidade muito intensa de metabolização de diversos compostos endógenos e exógenos.

Os sistemas em análise têm como estratégia inerente, a utilização desse metabolismo bacteriano para promo- ver a liberação específica de fármacos no cólon, mediante o recurso a pró-fármacos, formulações revestidas por polímeros biodegráveis ou matrizes e hidrogeis. É uma estratégia bastante específica, na medida em que estas bactérias apenas estão presentes no cólon. Não obstante alguns autores sugerem que a atividade enzimática é susceptível à dieta, fármacos e outros fatores externos pelo que a reprodutibilidade destes sistemas pode constituir um problema (Leopold, 1999).

\section{Pró-fármacos}

A utilização de pró-fármacos no âmbito dos sistemas baseados na microflora do cólon, envolve a formação de moléculas farmacologicamente inativas com características físico-químicas diferentes da molécula ativa. Devem cumprir os seguintes requisitos: não serem absorvidas pelo intestino delgado e, uma vez que alcancem o cólon, transformarem-se no composto farmacologicamente ativo mediante a ação metabólica da microflora bacteriana (Macleod, Tozer, 1992; Van der Mooter, Samyn, Kinget, 1992). A hidrofília ou o elevado peso molecular de alguns destes prófármacos, limita a sua absorção nas porções superiores do trato gastrointestinal (Macleod, Tozer, 1992). Os grandes incovenientes são: i) a sua aplicação limita-se a alguns fármacos pelo que não são sistemas universais, ii) requerem a modificação química do fármaco iii) não oferecem uma proteção contra o ambiente das regiões superiores do trato gastrointestinal tão eficaz quanto outros sistemas e iv) não permitem a administração de grandes quantidades de fármaco ou de vários fármacos (Ashford, Fell, 1994). As reações pelas quais o agente ativo pode ser libertado são de dois tipos: reduções azo e hidrólise. A composicão de diferentes pró-fármacos utilizados na liberação específica de fármacos no cólon encontra-se na Tabela 1.

\section{Azo-redução}

O exemplo clássico de um pró-fármaco que sofre azoredução para liberar especificamente o seu constituínte ativo no cólon é a sulfasalazina. Este fármaco foi inicialmente introduzido na terapêutica da artrite reumatóide ao combinar uma molécula de antibiótico, a sulfapiridina, e um salicilato, o ácido 5-aminosalicílico, unidos através de uma ligação azo (Figura 6) (Schröder, Lewkonia, Price-Evans, 1973).

O ácido 5-aminossalicílico é muito efetivo no tratamento da doença inflamatória do cólon. Contudo, mediante a sua administração oral sofre uma intensa absorção nas porções superiores do trato gastrointestinal, não exercendo uma ação local no cólon (Dash, Brittain, 1998). Pelo contrário, quando administrado sob a forma de sulfasalazina, pelo 
TABELA I - Composição de alguns pró-fármacos utilizados na liberação específica no cólon.

\begin{tabular}{lll}
\hline Princípio ativo & Ligando & Referência \\
\hline Ácido 5-aminossalicílico & Sulfapiridina & Schröder et al, 1973 \\
Ácido 5-aminossalicílico & Polímeros bioadesivos & Kope_ek, 1990 \\
Dexametasona & Glicosídio & Friend et al., 1992 \\
Budenosídio & Glicuronídio & Friend et al., 1995 \\
Naproxeno & Dextrano & Harboe et al., 1989 \\
& & Larsen et al., 1989 \\
Dexametasona & Dextrano & Macleod et al., 1992 \\
Metilprednisolona & Dextrano & Macleod et al., 1992 \\
Ácido 5-aminossalicílico & Ciclodextrina & Yano et al., 2001 \\
Ácido 5-aminossalicílico & Polímeros acrílicos & Davaran et al., 1999 \\
\hline
\end{tabular}

menos $85 \%$ de uma dose oral passa intacta pelo estômago e intestino delgado (Watts, Illum, 1997). O envolvimento da enzima azoreductase na redução de compostos com ligações azo é muitas vezes mencionado. No entanto, alguns estudos (Lloyd et al., 1993) apontam para o fato de a azoredução ser uma reação geral, mediada por moléculas de baixo peso molecular transportadoras de eletrons, como é o caso do NADPH.

O principal problema desta formulação são os seus efeitos secundários provocados pela absorção sistémica da sulfapiridina, tais como perimiocardites, pancreatites e diarreia (Azad Khan, Piris, Trueloves, 1977).

A necessidade de utilizar compostos menos tóxicos levou ao desenvolvimento de uma nova geração de prófármacos (Fig. 6). É o caso da olsalazina que consiste em duas moléculas de ácido 5-aminossalicílico ligadas por uma ligação azo, e da balsalazina que resulta da ligação azo entre o ácido 5-aminossalicílico e o composto 4aminobenzoil- $\beta$-alanina. Outro pró-fármaco, foi igualmente, sintetizado e testado. Denomina-se ipsalazina e é o resultado da ligação do ácido 5-aminossalicílico e de 4aminobenzoil- $\beta$-glicina.

No entanto, a utilização crônica destes compostos vai estar sempre associada a importantes efeitos adversos relacionados com a própria ligação azo (Milojevic et al., 1995a) os quais incluem efeitos carcinógenos, genotoxicidade e mutagenicidade (Miller, Miller, 1961).

Um novo conceito de liberação específica de fármacos, por via oral, foi proposta por Kopecek ao com-

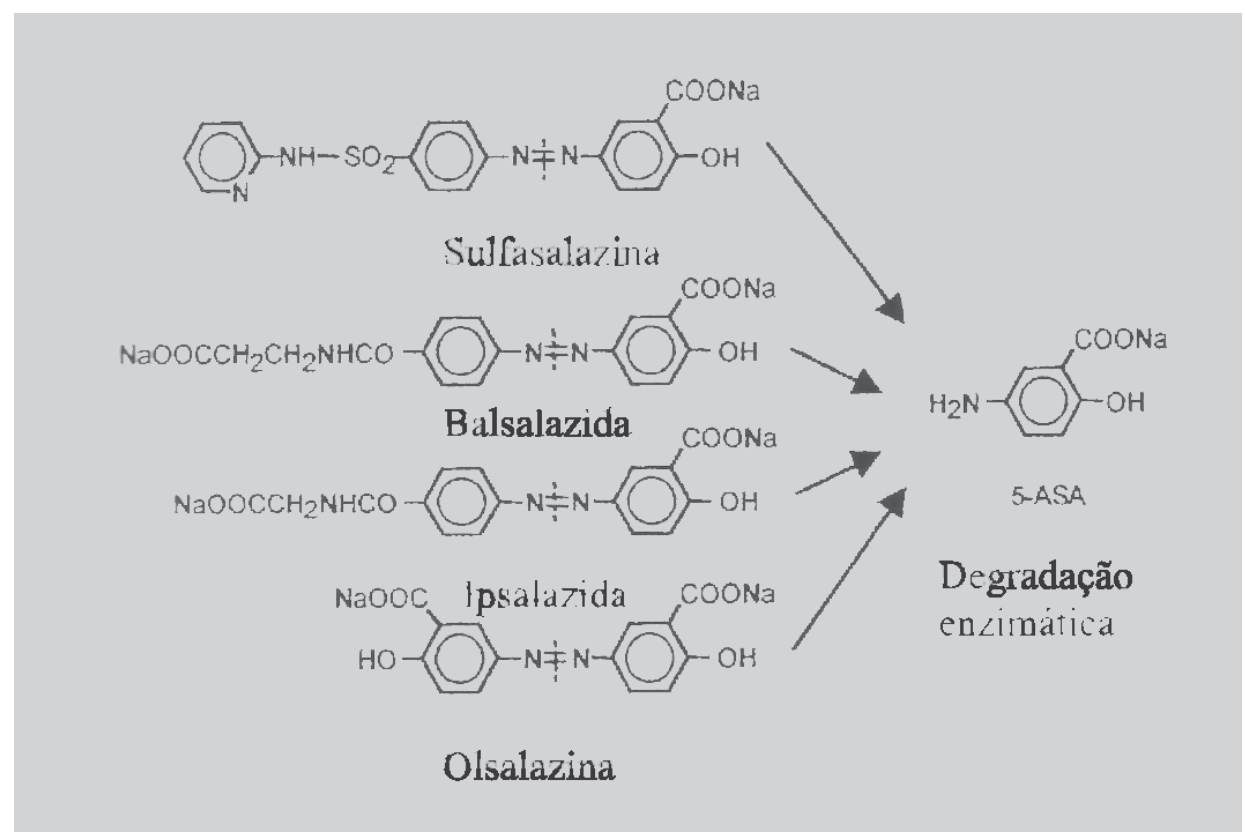

FIGURA 6 - Esquema da liberação do ácido 5-aminosalicílico a partir da sulfasalazina, balsalazida, ipsalazida e olsalazina. 
binar a liberação específica do ácido 5-aminosalicílico a partir de pró-fármacos com as propriedades bioadesivas do polímero transportador (Kopecek, 1990). Foram estabelecidas ligações azo entre o ácido 5-aminossalicílico e copolímeros de $N$-(2-hidroxipropil) metacrilamida (HPMA). À cadeia terminal deste polímero adicionaram açúcares complementares das lecitinas da mucosa do cólon, que ao interagir com os receptores das células epiteliais, facilita a intervenção das bactérias azoreductases e prolonga a liberação de fármaco no cólon evitando a sua eliminação prematura com as fezes (Macleod, Tozer, 1992). As características de bioadesão dos copolímeros de HPMA à mucosa do cólon ficaram demonstradas em modelos animais. Quando inoculado com Streptococum faecium, o ácido 5-aminossalicílico foi liberado desta formulação devido a ação das azoreductases (Kope_ek et al., 1992).

A grande limitação destas formulações é a elevada dose que tem de ser administrada ao longo do dia, para alcançar doses de 0,5-3 g de ácido 5-aminossalicílico, já que do peso total do medicamento apenas $20 \%$ corresponde a princípio ativo, sendo por isso mais conveniente utilizar outro fármaco que necessite de menores doses (Van der Mooter, Samyn, Kinget ,1995a).

\section{Hidrólise}

- Conjugados com glicosídeos

A conjugação de fármacos com glicosídeos é outra estratégia proposta na formulação de pró-fármacos destinados a liberação específica no cólon.

Os pró-fármacos formulados com glicosídeos são mais hidrofílicos e maiores do que o fármaco o que tende a reduzir a extensão de absorção a partir do trato gastrointestinal (Haeberlin et al., 1993). Uma vez no cólon, estes conjugados sofrem clivagem pela glicosidases bacterianas que aí existem em grande número, promovendo a liberação do princípio ativo. No entanto, alguns conjugados com glicosídeos podem sofrer degradação enzimática no trato gastrontestinal superior (Friend, Tozer, 1992).

Esta estratégia foi amplamente utilizada para a liberação de corticosteróides no cólon destinados ao tratamento local da doença inflamatória do intestino. O prófármaco, dexametasona ${ }^{2}$-D-glucósido, revelou-se estável quando colocado em várias soluções tampão com valores de $\mathrm{pH}$ entre 2,5 e 7,5: menos de $1 \%$ foi hidrolisado em 24 horas em todos os valores de $\mathrm{pH}$ testados. No entanto, foi rapidamente hidrolisado em homogeneizados de tecidos e de conteúdos luminais do cólon obtidos de modelos animais, sugerindo que a liberação do fármaco se deve à hidrólise provocada pelas glicosidades.

A eficácia comparativa da dexametasona e do seu pró-fármaco foi investigada em porcos da Índia aos quais foi induzida a doença inflamatória do intestino. Ficou evidente que $0,65 \mu \mathrm{mol} / \mathrm{kg}$ de dexametasona $\beta$-Dglucósido é tão efetivo quanto $1,3 \mu \mathrm{mol} / \mathrm{kg}$ de dexametasona, na redução do número total de úlceras, pelo que os efeitos secundários associados a esta terapêutica podem ser reduzidos sem comprometer a sua eficácia (Friend, Tozer, 1992).

\section{- Conjugados com glicoronídios}

A utilização de glucorônidos na preparação de prófármacos destinados a liberar o seu componente ativo no cólon surgiu na sequência de duas observações: i) estes conjugados são mais hidrofílicos do que os glicosídeos pelo que a sua absorção no intestino delgado é menor e ii) a atividade das enzimas glucuronidases no intestino delgado é mais baixa.

Perante estas vantagens sob os pró-fármacos obtidos com glicósidos, Friend (1995) sintetizou dois pró-fármacos de componentes ativos utilizados no tratamento da doença inflamatória do intestino: mentol- $\beta$-D-glicoronídio e budenosido$\beta$-D-glucorónido, observando que a velocidade de degradação destes compostos entre o intestino delgado e o cólon de ratos aumentava cerca de 90 vezes no caso do budenosido- ${ }^{2}$-Dglucorónido. Estes resultados, sugerem que ambos os prófármacos apresentam uma absorção neglicenciável através do trato gastrointestinal. A baixa absorção associada a um gradiente elevado de hidrólise enzimática entre o intestino delgado e cólon, demonstra o seu potencial para liberar agentes terapêuticos especificamente no cólon. Além disso, estas observações podem ser otimizadas no caso do homem, na medida que este apresenta uma menor atividade de $\beta$-Dglucuronidases no intestino delgado.

Haeberlin (Haeberlin et al., 1993) investigaram o potencial, in vitro, da dexametasona $\beta$-D-glicoronídio e obtiveram resultados similares aos anteriores.

\section{- Conjugados com dextranos}

Os pró-fármacos obtidos a partir da conjugação com dextranos, são degradados pelas dextranases e estereases presentes no cólon. Esta estratégia apresenta-se promissora na entrega específica de fármacos no cólon no âmbito de algumas patologias colónicas, dado que as espécies Bacteroides, que correspondem a cerca de $20 \%$ da microflora fecal humana, secretam algumas dextranases e estão presentes na flora fecal de pacientes que sofrem de colite ulcerosa e doença de Crohn (Larsen et al., 1989). 
As dextranases classificam-se em dois grupos em função do produto que formam através da hidrólise enzimática.: as endodextranases e as exodextranases. As primeiras promovem a quebra de ligações glicosídicos $\alpha-1,6$ e $\alpha-1,3$ da cadeia polimérica, provocando quer uma redução do peso molecular, quer da viscosidade. As endodextranases atuam rompendo as ligações terminais, libertando mono e dissacarídeos (Macleod, 1992).

Harboe et al. (1989) estudaram a biodisponibilidade oral do naproxeno em porcos da Índia a partir de ésteres do naproxeno-dextrano com diferentes pesos moleculares. Concluíram que este pró-fármaco possui várias características de um bom sistema de liberação específica: i) o prófármaco intacto não atinge a circulação sistémica; ii) não sofre degradação enzimática no conteúdo do intestino delgado; iii) a regeneração seletiva do naproxeno ocorre no cego e cólon e iv) a biodisponibilidade do naproxeno a partir de todos os pró-fármacos preparados foi quase de $100 \%$.

Num estudo posterior (Larsen et al., 1989), comparou-se a velocidade de liberação destes pró-fármacos em homogeneizados de vários segmentos do trato gastrointestinal do porco. A liberação foi 15 a 17 vezes mais rápida nos homogeneizados do conteúdo do cego e cólon do que num tampão de $\mathrm{pH}$ 7,4 ou homogeneizado de conteúdo do intestino delgado.

Macleod e colaboradores (Macleod, Friend, Tozer, 1993) analisaram, com êxito, a união da dexametasona e metilprednisolona ao dextrano através do ácido succínico. Este pró-fármaco demonstrou elevada estabilidade nos conteúdos do intestino delgado e rápida ativação mediante hidrólise pelas bactérias do cólon.

\section{- Conjugados com ciclodextrinas}

As ciclodextrinas são oligassarídeos cíclicos passíveis de fermentação pelas polissacaridases presentes no cólon. Estes compostos são pouco hidrolisados e apenas ligeiramente absorvidos durante a sua passagem pelo estômago e intestino delgado (Yano et al., 2002). Estas duas características levaram ao desenvolvimento de prófármacos do ácido 5-aminosalicílico que resultam da união a ciclodextrinas (Zou et al., 2004).

Uma vez que as doses diárias deste fármaco no tratamento de doenças do cólon é muito elevado, o grau de substituição da ciclodextrina, isto é, o número de moléculas de 5-ASA ligados à molécula de ciclodextrina, deve ser o mais elevado possível, sem que, contudo, a solubilidade do pró-fármaco seja tão baixa que comprometa a liberação do princípio ativo no cólon.

Além disso, a solubilidade da ciclodextrina deve ser considerada pois afeta a solubilidade do pró-fármaco e consequentemente a liberação do 5-ASA. Neste contexto, a liberação do ácido 5-aminosalicílico nos conteúdos do cólon e cego foi superior quando se utilizou a ciclodextrina mais solúvel ( $\gamma$-ciclodextrina). Por outro lado, independentemente do tipo de ciclodextrina e sua solubilidade quando se procedeu à incubação em conteúdos do estômago e intestino delgado verificou-se uma liberação do 5-ASA muito baixa.

\section{- Conjugados com polímeros acrílicos}

Outra estratégia utilizada na liberação específica de fármacos no cólon baseia-se na união do ácido 5aminosalicílico a polímeros acrílicos dando lugar a prófármacos que possuem ligações amida ou éster biodegradáveis. É o caso do metacriloiloxetil 5-aminosalicilato e do $N$-metacriloilaminoetil 5-aminosalicilato (Davaran, Hanaee, Khosravi, 1999). A eficácia destes sistemas é dependente de seu grau de intumescimento nas regiões do trato gastrointestinal que antecedem o cólon. Em meios com pH baixo, estes polímeros devem exibir um grau de intumescimento baixo, reduzindo a possibilidade de hidrólise. Contudo, quando o $\mathrm{pH}$ aumenta, o grau de intumescimento torna-se mais significativo, tornando-os mais susceptíveis à hidrólise. No entanto, se levarmos em conta o fato de que não existe um significativo gradiente de $\mathrm{pH}$ entre o intestino delgado e cólon, então uma quantidade considerável de fármaco pode ser liberada no intestino delgado devido à hidrólise do polímero intumescido, o que torna estes sistemas pouco eficazes na liberação específica de fármacos no cólon.

- Revestimento com polímeros biodegradáveis

O revestimento de diferentes formas farmacêuticas com polímeros biodegradáveis tem sido proposto como mecanismo de liberação seletiva de fármacos no cólon.

As duas principais classes de polímeros utilizados no revestimento de sistemas de liberação específica de fármacos no cólon são os polímeros sintéticos com ligações azo, e os polímeros naturais.

Os excipientes utilizados no revestimento devem obedecer a determinados requisitos: proteger o fármaco no conteúdo gástrico e do intestino delgado e assegurar uma liberação rápida do princípio ativo, predominantemente no cego (Bauer, Kesselhut, 1995). Para isso devem: i) ser insolúveis em água em qualquer valor de $\mathrm{pH}$, ii) suceptíveis a degradação pelas bactérias do cólon, iii) solúveis ou dispersíveis em solventes adequados às formulações de revestimento, iv) mostrar capacidade para formar filmes e v) ser isentos de toxicidade (Bauer, 
Kessehult, 1995). A formulação de comprimidos, cápsulas ou peletes com polímeros biodegradáveis oferece duas grandes vantagens: especificidade no local de liberação do princípio ativo e administração de quantidades ilimitadas de um fármaco (Van der Mooter, Samyn, Kinget, 1993).

$\mathrm{O}$ grande inconveniente é a dificuldade em obter revestimentos reprodutíveis. Para além disso, sendo o esvaziamento gástrico a parte mais variável do trânsito gastrointestinal, as formas farmacêuticas revestidas podem ser afetadas por alterações deste trânsito (Liu et al., 2003).

\section{- Revestimento com polímeros sintéticos}

Van Der Mooter et al. (1992) sintetizaram novos polímeros azo através da incorporação de um composto bifuncional azo, o bis(metilcriolamina)azobenzeno (BMAAB), em copolímeros do 2-hidroxietil metacrilato (HEMA) e do metacrilato de metila (MMA). Após a sua análise in vitro e in vivo, concluíram que os revestimentos por filme constituídos por estes polímeros são degradados pelas bactérias intestinais. Contudo, deve ser equacionada a relação entre a quantidade de componentes hidrofílicos, que asseguram a acessibilidade aos grupos azo, e os componentes hidrofóbicos que conferem maior resistência ao suco gástrico e fluídos do intestino delgado.

Após inclusão cirúrgica de cápsulas revestidas por polímeros azo e contendo teofilina como fármaco modelo no intestino delgado e cego de ratos, observaram-se concentrações plasmáticas de teofilina superiores, quando as cápsulas eram inseridas no cego (Van der Mooter, Samyn, Kinget, 1995b) o que demonstrou que a liberação da teofilina é o resultado combinado da difusão e degradação do polímero azo pelas azorredutases. Contudo, foi verificada a absorção da teofilina a partir do intestino delgado, como consequência da simples difusão do fármaco através do polímero intumescido.

Outro grande grupo de polímeros sintéticos degradáveis no cólon é formado pelas poliamidas lineares e poliuretanos (Kimura et al., 1992). Schacht et al. (1996) demonstraram que as poliamidas que contém grupos azo na sua estrutura são reduzidas em meio colônico. Dependendo da natureza do polímero, a redução pode resultar na ruptura da cadeia ou deter-se no momento em que se forma a hidrazina. Neste último caso, o revestimento permanece intacto, mas as trocas físicas que ocorrem, tornam-os passíveis de ser utilizados na formulação de sistemas de liberação colônica.

\section{- Revestimento com polímeros naturais}

O princípio de utilização de sistemas revestidos por polissacarídeos é a existência de quantidades significativas de polissacaridases no cólon humano o que favorece a liberação seletiva de fármacos nesse local (Rubinstein $e t$ al., 1997). Além disso, estes materiais possuem uma baixa toxicidade e uma significativa capacidade para gelificar. No entanto, apresentam alguns inconvenientes, como a fragilidade das suas membranas e a sua elevada hidrofilia, tornando-os muito solúveis nos fluidos gástrico e intestinal, dando origem a difusões prematuras do fármaco. Aliando isso, ao fato de alguns polissacarídeos, serem degradados nas porções superiores do trato gastrointestinal, constitui uma barreira ao seu uso isolado.

Algumas estratégias foram investigadas quer no sentido de melhorar as propriedades mecânicas dos filmes, quer com o intuito de reduzir a solubilidade destes compostos. Bauer e Kesselhut (1995) propuseram a reticulação de galactomananos e a união de dextranos a ácidos gordos, como o ácido capróico, por forma a diminuir a solubilidade destes compostos e melhorar as características dos seus filmes.

No entanto, do ponto de vista da concepção destes sistemas, estas estratégias tornam a sua reprodutibilidade um problema. Apesar disso, a utilização de polímeros naturais no revestimento de sistemas de liberação específica de fármacos no cólon tem constituído, nos últimos anos, a base de vários trabalhos científicos. De seguida, descrevem-se alguns desses trabalhos com ênfase nas estratégias que têm sido adotadas para contornar as limitações destes compostos.

A amilose é um polissacarídeo que possui capacidade de formar geis e filmes (Milojevic et al., 1995a) que apresentam uma microestrutura potencialmente resistente à ação da $\alpha$-amilase pancreática mas passível de ser digerida pelas amilases da microflora do cólon (Milojevic et al., 1995b). A fragilidade destes filmes e o elevado grau de intumescimento na presença de água, obriga à adição de agentes estruturantes, como, por exemplo, a etilcelulose, que é adicionada sob a forma de dispersões aquosas ou de soluções orgânicas. A incorporação de Ethoce ${ }^{\circledR}$ em revestimentos de amilose permitiu uma supressão da liberação in vitro, do fármaco, pelo período de 12 horas (Milojevic et al., 1995a) e não comprometeu a sua susceptibilidade para sofrer degradação enzimática (Siew et al., 2004).

Em estudos posteriores (Milojevic et al., 1995c) prepararam-se peletes revestidos com amilose e Ethocel ${ }^{\circledR}$ numa relação de 1:4. O fármaco modelo utilizado foi a glucose marcada $\operatorname{com}^{13} \mathrm{C}$ e a validação do revestimento realizou-se determinando o ${ }^{13} \mathrm{CO}_{2}$ no ar expirado e por $\gamma$-cintigrafia. $\mathrm{O}$ ${ }^{13} \mathrm{CO}_{2}$ apareceu na respiração 7 horas após administração e o tempo de chegada ao cólon, avaliado através dos estudos de $\gamma$-cintigrafia foi de 4,5 horas. Esta diferença de 2,5 horas 
parece dever-se ao tempo que as enzimas demoram a degradar o revestimento e libertar a glucose.

A pectina é um polissacarídeo heterogêneo composto, majoritariamente, por ácido galacturônico e o seu éster metílico (Ashford et al., 1994). É resistente à ação das enzimas presentes no estômago e intestino delgado e é, quase completamente, degradada pelas bactérias do cólon, produzindo uma série de oligogalacturonatos solúveis. De acordo com o seu grau de metoxilação, as pectinas apresentam distintas solubilidades. Assim, as pectinas com elevado grau de metoxilação são menos solúveis enquanto que as mais solúveis são caracterizadas por um baixo grau de metoxilação. A elevada solubilidade de algumas pectinas pode ser reduzida mediante a reticulação com cátions bivalentes como é o caso do cálcio ou zinco (ElGibaly, 2001). Deste modo, quer as pectinas com elevado grau de metoxilação, quer as pectinas com menor grau de metoxilação, mas formuladas com uma quantidade controlada destes elementos, constituem mecanismos passíveis de maximizar a especificidade na liberação colônica, assegurando uma proteção eficaz durante o trânsito pelo cólon e uma elevada susceptibilidade para sofrer degradação enzimática (Ashford et al., 1994).

O pectinato de cálcio foi utilizado no revestimento de peletes de teofilina (Sriamornsak et al., 1997). A liberação in vitro, da teofilina foi testada em água, tampão $\mathrm{pH}$ 7,4 e suco gástrico artificial. Em geral, a liberação foi constante até que cerca de 75 a $80 \%$ do fármaco fosse libertado e independente do meio de dissolução, do tipo de pectina e do tempo de revestimento. O efeito mais marcante foi o tamanho do núcleo dos peletes, sendo que os de maiores dimensões com menores superfícies de contacto e mais extensas vias de difusão, demonstraram velocidades lentas de liberação da teofilina. Concluíu-se que o revestimento com pectinato de cálcio é fácil de aplicar e confere perfis de liberação relativamente independentes do $\mathrm{pH}$.

Para além da utilização de pectinato de cálcio, a combinação da pectina com polímeros naturais ou sintéticos insolúveis em água, tem sido intensamente investigada. Esses polímeros incluem: etilcelulose (Zeitoun, Brisard, 1988), hidroxipropilmetilcelulose (Turkoglu, Ugurlu, 2002), Eudragit ${ }^{\mathbb{R}}$ (Semdé et al., 2000a, b) e quitosana (Fernandez-Hervás, Fell, 1998; Macleod et al., 1999).

Uma formulação de ácido 5-aminosalicílico revestida por diferentes proporções desses dois polímeros ( $100 \%$ de pectina, $80 \%$ de pectina- $20 \%$ de HPMC, e $60 \%$ de pectina- $40 \%$ de HPMC) foi concebida de acordo com o conceito de tempo de trânsito gastrointestinal, assumindo um tempo de chegada ao cólon de 6 horas. A concentração ótima de HPMC foi de $20 \%$, e este sistema conse- guiu proteger o núcleo por mais de 6 horas, o que corresponde a $25-30 \%$ de erosão, seguida de liberação rápida do ácido 5-aminosalicílico no cólon mediante degradação enzimática.

A capacidade de revestimentos constituídos por pectina e quitosana na relação de 1:10 foi avaliada quando aplicada em comprimidos de pequenas dimensões e usando como fármacos modelo, a indometacina (pouco hidrossolúvel) e o paracetamol (hidrossolúvel). Esta combinação confere um maior grau de proteção da liberação prematura dos fármacos nas porções superiores do trato gastrointestinal do que o revestimento composto, apenas, por pectina, sendo este efeito mais sentido quando se utilizam fármacos insolúveis como a indometacina. Na realidade, o paracetamol mostrou uma liberação prematura em condições que simulam as condições do trato gastrointestinal superior (Fernandez-Hervás, Fell, 1998).

A inulina é um polissacarídeo resistente à hidrólise e digestão no trato gastrointestinal superior e fermentado pela microflora do cólon (Vervoort, Kinget, 1996). Para além da sua elevada hidrofilia, este composto natural não tem capacidade para formar filmes com características adequadas ao revestimento de formas farmacêuticas. De modo a formular este composto como material de revestimento biodegradável, a sua solubilidade foi reduzida através de um elevado grau de polimerização e, posteriormente, incorporada em filmes de Eudragit ${ }^{\mathbb{R}} \mathrm{RS}$ (Vervoort e Kinget, 1996). Esta formulação demonstrou ser capaz de manter a sua integridade nos fluídos gástrico e intestinal e ser susceptível a degradação enzimática.

$\mathrm{O}$ Eudragit ${ }^{\circledR} \mathrm{RS}$ foi igualmente, utilizado no revestimento de comprimidos de ácido 5-aminosalicílico em combinação com a $\beta$-ciclodextrina (Fetzner et al., 2004).

Até ao momento, o único polissacarídeo utilizado isoladamente no revestimento de sistemas de liberação específica de fármacos no cólon foi a goma guar (Krishnaiah et al., 1998a). Este composto é amplamente utilizado em formulações farmacêuticas como agente desintegrante, estabilizante e espessante.

Quando comprimidos de indometacina revestidos por goma guar foram administrados a voluntários humanos e o seu percurso no organismo avaliado por ${ }^{3}$ cintilografia concluíu-se que esta formulação permanecia intacta no estômago e intestino delgado. A degradação do revestimento iniciou-se à entrada do cólon ascendente devido à atividade das bactérias que aí residem.

\section{- Matrizes e hidrogeis}

Alguns polissacarídeos têm sido utilizados na formulação de matrizes, como é o caso da pectina 
(Rubinstein et al., 1993; El-Gibaly, 2002), goma guar (Prasad, Krishnaiah e Satyanarayana, 1998), quitosana (Zhang, Alsarra e Neau, 2002) e sulfato de condroitina (Rubinstein et al., 1992a). Os sistemas matricias apresentam a vantagem de serem utilizados, em larga escala, pela indústria farmacêutica sem necessidade de recorrer a equipamento muito sofisticado (Liu et al., 2003). Apesar disso, a elevada hidrofilia dos polissacarídeos representa, sobretudo nestes sistemas, uma grande limitação, pelo que a sua utilização restringe-se a fármacos pouco solúveis. Outro incoveniente é a morosidade da degradação enzimática de uma matriz constituída por polissacarídeos, que pode requerer mais de 12 horas para se completar (Yang, Chu e Fix, 2002).

Neste sentido, as matrizes que têm sido preparadas requerem uma pré-modificação dos polissacarídeos com o intuito de reduzir a sua solubilidade. É o caso da pectina (Rubinstein, Sintov, 1992) e do sulfato de condroitina (Rubinstein, Nakar, Sintov, 1992a) que necessitam de sofrer reticulação.

O sulfato de condroitina é um mucopolissacarídeo hidrossolúvel que serve de substrato às bactérias do cólon, sobretudo Bacteroides. Rubinstein et al. (1992a) ensaiaram matrizes de sulfato de condroitina reticulada com 1,12diaminododecano, utilizando o composto diciclohexil carbodiimida como catalisador e a indometacina como fármaco modelo. O sulfato de condroitina, apesar de se encontrar reticulado, mostrou-se passível de ser degradado pelas bactérias exitentes no cego (Rubinstein, Nakar, Sintov, 1992b).

Outro tipo de sistemas que se degradam unicamente no cólon são os hidrogéis. Alguns destes sistemas contém monômeros ácidos e reticulações azo aromáticas que são degradadas por enzimas azoredutoras (Duchene, Ponchel, 1993). O grau de intumescimento do hidrogel, nas condições ácidas do estômago, é muito baixo, prevenindo, assim, a degradação do princípio ativo por parte das enzimas digestivas. À medida que o $\mathrm{pH}$ vai aumentando ao longo do trato gastrointestinal, o grau de intumescimento aumenta, como consequência da ionização e repulsão das cargas do hidrogel. No cólon, o grau de intumescimento é tal, que as reticulações estão acessíveis às enzimas azoredutases, promovendo a liberação do fármaco (Kopecek et al.,1992).

O mecanismo e a velocidade de degradação de um hidrogel estão diretamente relacionados com a estrutura $\mathrm{e}$ longitude do agente reticulante, com a densidade da rede polimérica resultante e com o grau de intumescimento destes sistemas. Se a densidade de reticulação é muito elevada, há uma menor degradação, dado que a acessibilidade por parte das enzimas às reticulações é menor e o número de reticulações que se têm de degradar é superior. Do mesmo modo, entre hidrogéis que apresentem a mesma densidade mas diferentes longitudes do agente reticulante, o intumescimento e a velocidade de degradação será superior para aqueles que apresentam maior longitude (Duchene, Ponchel,1993).

Para além destes hidrogéis, também se sintetizaram outros hidrogéis biodegradáveis a partir do dextrano (Brønsted, Hovgaard, Simonsen,1995a; Simonsen et al., 1995; Hovgaard, Brønsted, 1995), goma guar (Krishnaiah et al., 1998b) e inulina (Vervoort et al., 1998a; Vervoort et al., 1998b).

Brøndsted e colaboradores (1995a) demonstraram que os hidrogéis de dextrano são degradados in vitro por uma preparação de dextranases, e, in vivo, no cego de ratos.

Em estudos posteriores, os mesmos investigadores (Brønsted, Hovgaard, Simonsen, 1995b) avaliaram a potencialidade dos hidrogéis de dextrano na liberação colônica da hidrocortisona e do fosfato sódico de prednisolona. A liberação da hidrocortisona, que é um fármaco hidrofóbico, mostrou ser controlada por mecanismos de difusão e proporcional à densidade de reticulação do hidrogel. A liberação do fosfato sódico de prednisolona é controlada pelo grau de intumescimento e é inversamente proporcional à densidade de reticulação do hidrogel. Assim, para o fármaco hidrofílico, tanto na presença como na ausência de dextranases, o sistema apresenta uma rápida liberação do fármaco. Contrariamente, quando o fármaco é mais hidrofóbico e na ausência de enzimas a velocidade de liberação é lenta, mas aumenta drasticamente na presença de dextranases. Este fato sugere que os hidrogéis de dextrano são adequados para a liberação no cólon de fármacos hidrofóbicos.

O incoveniente das matrizes e hidrogéis face ao revestimento por polímeros biodegradáveis é que a quantidade de fármaco é limitada, não sendo viável para certos princípios ativos, como é o caso do ácido 5-aminossalicílico, que apenas é efetivo em doses elevadas (Van der Mooter et al., 1995).

\section{SISTEMAS BASEADOS NA PRESSÃO INTRALUMINAL DO CÓLON}

Outra estratégia para promover a liberação específica de fármacos no cólon baseia-se na presença de ondas peristálticas vigorosas que aí ocorrem e que conduzem a um aumento da pressão intraluminal. As formulações designadas de $\mathrm{PCDC}^{\circledR}$ ("Pressure control colon delivery capsule"), consistem em cápsulas cuja liberação específica no cólon é controlada pela pressão. As cápsulas apresentam a forma de supositórios de polietilenoglicóis (PEG), revestidas por etilcelulose 
(Takaya et al., 1995; Hu et al., 2000a; Shibata, et al., 2001). Quando administradas oralmente, vão comportar-se como um "balão" de etilcelulose, uma vez que a sua base se liquefaz à temperatura corporal. No trato gastrointestinal superior, estas cápsulas não estão diretamente sujeitas a pressões luminais, dado que existe sempre fluído no estômago e intestino delgado e, como tal, mantêm a sua integridade.

Com base na limitada avaliação in vivo destes sistemas, demonstrou-se que a sua capacidade para liberar fármacos especificamente no cólon, depende da espessura do filme de etilcelulose e do tamanho da cápsula: à medida que a espessura aumenta, aumenta a fase de latência $(\mathrm{Hu}$ et al., 1998). Alguns investigadores (Hu et al., 2000b), avaliaram os tempos de trânsito gastrointestinal destes sistemas. Quando administrados oralmente, em humanos usando a cafeína como fármaco modelo, observou-se que em dois indivíduos as cápsulas chegavam ao cólon 4 e 5 horas após administração. Nesses mesmos indivíduos, detectaram-se níveis de cafeína na saliva 6 a 5 horas, respectivamente, após administração oral. Estes resultados confirmam a eficácia destes sistemas na liberação especifíca de fármacos no cólon, ao retardar a liberação da cafeína até que se atinja o íleo terminal ou cólon ascendente. No entanto, deve ser referido que o conhecimento sobre esta fase de pressão aumentada é muito limitado, nomeadamente no que respeita à sua reprodutibilidade e duração. Na realidade, pensa-se que as maiores ondas peristálticas surgem, apenas, uma a duas vezes por dia de acordo com um ritmo circadiano (Yang, Chu, Fix, 2001) pelo que a reprodutibilidade destes sistemas pode constituir uma séria limitação ao seu uso.

\section{CONCLUSÕES}

A revisão apresentada pode suscitar algumas questões mais pertinentes em relação à eficácia dos vários sistemas de liberação específica no cólon. Avaliar e comparar a eficácia destes sistemas implica conhecer qual o seu principal objectivo, isto é, liberar um fármaco em locais específicos do cólon, onde se reconheçam vantagens terapêuticas, quer do ponto de vista do tratamento local de patologias colônicas, quer na absorção sistêmica de determinados fármacos.

Os sistemas que se baseiam na microflora e enzimas do cólon mostram ser os mais específicos, enquanto que os sistemas tempo e pH-dependentes, apesar de menos específicos, são igualmente eficazes. Na realidade, todas as estratégias apresentadas são em maior ou menor extensão afetadas pelas variações das condições fisiológicas intra e interindividuais. Se o pH e tempo de trânsito intestinal são variáveis, a composição quantitativa da microflora colónica pode, igualmente, ser afetada por fatores como a dieta, fármacos, idade e patologias. Adicionalmente, a primeira parte desta revisão deixou bem patente que algumas patologias, como é o caso da doença inflamatória do intestino, podem ter um impacto muito negativo na eficácia destes sistemas. Neste contexto, talvez o sistema mais específico de liberação de fármacos no cólon possa tirar partido das suas condições patológicas, isto é, do fato de vários estudos sugerirem que as doenças inflamatórias do intestino, como a colite ulcerosa, são caracterizadas por uma diminuição dos valores normais de $\mathrm{pH}$ de 6,4-7,0 para valores de 2,3-3,7. O mecanismo utilizado para a liberação consistiria no revestimento de uma forma farmacêutica com um polímero ácido-solúvel, que assegure a liberação do agente farmacológico seletivamente no local ativo de doença onde o $\mathrm{pH}$ é mais baixo. No entanto, para garantir a sua integridade até que chegue ao cólon, este sistema deverá ser revestido externamente por um polímero entérico. A grande vantagem deste sistema sob os convencionais sistemas $\mathrm{pH}$-dependentes é o fato de aliar a facilidade de produção das formulações revestidas por polímeros $\mathrm{pH}$-dependentes, às características fisiológicas e patológicas do cólon e, assim, garantir a máxima especificidade e eficácia.

O mecanismo utilizado para a liberação é, sem dúvida, o aspecto mais importante na concepção de um sistema de liberação específica de fármacos no cólon. No entanto, existem outros fatores fundamentais, como a escolha da forma farmacêutica. Na perspectiva do desenvolvimento de formas farmacêuticas estes sistemas devem apresentar um design simples, facilidade de produção em grande escala e a um custo reduzido. Os sistemas mais complexos podem oferecer dificuldades na produção e reprodutibilidade. Estes requisitos podem ser conseguidos com o recurso a sistemas multiparticulados como peletes, que como já foi discutido apresentam várias vantagens sob os comprimidos ou cápulas.

As matrizes, sobretudo as que utilizam polissacarídeos hidrossolúveis, não conferem um grau de protecção aceitável nas condições presentes no trato gastrointestinal superior, em particular quando se tratam de fármacos solúveis. Neste sentido, as formulações revestidas constituem a melhor alternativa. Além disso, e tal como foi discutido ao longo desta revisão, o tratamento da doença inflamatória com o ácido 5-aminossalicílico e corticosteróides, requer doses diárias elevadas destes compostos e as formulações revestidas possibilitam a administração de doses ilimitadas de fármaco, resultando numa maior conveniência de dosificação.

Para concluir, as investigações futuras neste campo, 
devem ser conduzidas por forma a identificar a estratégia apropriada, que permita a liberação específica do fármaco de uma maneira segura, efetiva, pouco dispendiosa e com a mínima flutuação em termos de liberação de fármacos no local alvo. Esta revisão deixou em aberto a possibilidade de conceber um sistema $\mathrm{pH}$-dependente que poderá ser muito vantajoso no tratamento da doença inflamatória do intestino.

\section{ABSTRACT}

\section{Colonic drug delivery. II- Types of delivery systems}

Two basic approaches may be taken in delivering drugs to the colon: time-delayed release or colonic targeting. The former involves sustained release dosage forms, which are designed to prolong drug dissolution and hence absorption, until it reaches the colon. This strategy shows lack of specificity when compared with others that take advantage of unique characteristics present in the colon. Direct targeting involves the exploitation of environmental properties of the colon, like $\mathrm{pH}$ of the colon, enzymatic activity or intraluminal pressure. In general, the ideal colonic drug delivery may be accomplished by using pellets, which are known to have more predictable gastric emptying and great colonic residence times, and coated dosage forms with a simple design since they are easy to manufacture. Theoretically, the enzyme dependent systems, and, specially, those based in the use of polysaccharides, are more specific and non-toxic. Nevertheless, any of the others approaches might be suitable to obtain a colonic delivery system with the appropriate characteristics. Some commercially timedependent and $\mathrm{pH}$-dependent systems have shown important benefits in the treatment of inflammatory bowel disease, despite their less specificity. The investigations in this field should be conducted to identify the appropriate approach, which can result in the delivery of drugs in a safe, effective and less expensive manner with minimum fluctuation in terms of release of drug at target site.

UNITERMS: Colon specific delivery. Time-dependent systems. pH-dependent systems. Systems based on the colonic microflora. Systems based on the intraluminal pressure.

\section{REFERÊNCIAS BIBLIOGRÁFICAS}

ASHFORD, M.; FELL, J. T. Targeting drugs to the colon: delivery systems for oral administration. J. Drug Target., London, v. 2, p. 241-258, 1994.
ASHFORD, M.; FELL, J. T.; ATTWOOD, D.; SHARMA, H.; WOODHEAD, P. J. An vivo investigation into the suitability of pH-dependent polymers for colonic targeting. Int. J. Pharm., Amsterdam, v. 95, p. 193-199, 1993a.

ASHFORD, M.; FELL, J. T;; ATTWOOD, D.; WOODHEAD, P. J. An in vitro investigation into the suitability of $\mathrm{pH}-$ dependent polymers for colonic targeting. Int. J. Pharm., Amsterdam, v. 91, p. 241-245, 1993 b.

ASHFORD, M.; FELL, J. T.; ATTWOOD, D.; SHARMA, H.; WOODHEAD, P. J. Studies on pectin formulations for colonic drug delivery. J. Control. Release, Amsterdam, v. 30, p. 225-232, 1994.

AZAD KHAN, A. K.; PIRIS, J.; TRUELOVES, C. An experiment to determine the active therapeutic moiety of sulphasalazine. Lancet, London, v. 2, p. 892-895, 1997.

BAUER, K. H.; KESSELHUT, J. F. Novel pharmaceutical excipients for colon targeting. S.T.P. Pharma Sci., Paris, v. 5, n. 1, p. 54-59, 1995.

BRØNDSTED, H.; HOVGAARD, L.; SIMONSEN, L. Dextran hydrogels for colon-specific drug delivery. III. In vitro and in vivo degradation. S.T.P. Pharma Sci., Paris, v. 5, n. 1, p. 60-64, 1995a.

BRØNDSTED, H.; HOVGAARD, L.; SIMONSEN, L. Dextran hydrogels for colon-specific drug delivery. IV. Comparative release study of hydrocortisone and prednisolone sodium phosphate. S.T.P. Pharma Sci., Paris, v. 5, n. 1, p. 65-69, 1995 b.

BRUNNER, M.; GREINWALD, R.; KLETTER, K.; KVATERNIKS, H.; CORRADO, M. E.; EIGHLER, H. G.; MULLER, M. Gastrointestinal transit and release of 5-aminosalicylic acid from $153 \mathrm{Sm}$-labelled mesalazine pellets vs. tablets in male healthy volunteers. Aliment.Pharmacol. Ther., London, v. 17, p.1163-1169, 2003.

DASH, A.K.; BRITTAIN, H.G. Mesalamine. In: BRITTAIN, H.G., (Ed.). Analytical profiles of drug substances and excipients. New York: Academic Press, 1998., v. 25, p.209-242.

DAVARAN, S.; HANAEE, J.; KHOSRAVI, A. Release of 5amino salicylic acid from acrylic type polymeric prodrugs designed for colon-specific drug delivery. $J$. Control. Release, Amsterdam, v. 58, p. 279-287, 1999. 
DEW, M. J.; HUGHES, P.J.; LEE, M. G.; EVANS, B. K.; RHODES, J. An oral preparation to release drugs in the human colon. Br. J. Clin. Pharmc., London, v. 14, p. $405-$ 408, 1982.

DUCHENE, D.; PONCHEL, G. Colonic administration, development of drug delivery systems, contribution of bioadhesion. S.T.P. Pharma Sci., Paris, v. 3, p. 277-285, 1993.

EL-GIBALY, I. Oral delayed-release system based on Znpectinate gel (ZPG) microparticles as an alternative carrier to calcium pectinate beads for colonic drug delivery. Int. J. Pharm., Amsterdam, v. 232, p. 199$211,2002$.

FERNÁNDEZ-HERVÁS, M. J.; FELL, J. T. Pectin/ chitosan mixtures as coatings for colon-specific drug delivery: an in vitro evaluation. Int. J. Pharm., Amsterdam, v. 169, p. 115-119, 1998.

FETZNER, A.; BÖHM, S.; SCHREDER, S.;SCHUBERT, $\mathrm{R}$. Degradation of raw or film film-incorporated ${ }^{2}$ cyclodextrin by enzymes and colonic bacteria. Eur. J. Pharm. Biopharm., Stuttgart, v. 58, p. 91-97, 2004.

FRIEND, D. R.; TOZER, T. N. Drug glycosides in oral colonspecific drug delivery. J. Control. Release, Amsterdam, v. 19, p. 109-120, 1992.

FRIEND, D.R. Glycoside prodrugs: novel pharmacotherapy for colonic diseases. STP Pharma Sci., Paris, v. 5, n. 1, p. 70-76, 1995.

GAZZANIGA, A.; IAMARTINO, P.; MAFFIONE, G.; SANGALLI, M. E.; Oral delayed-release system for colonic specific delivery. Int. J. Pharm., Amsterdam, v.108, p. 77-83, 1994.

GAZZANIGA, A.; BUSETTI, C.; MORO, L.; SANGALLI, M. E.; GIORDANO, F. Time-dependent oral delivery systems for colon targeting. S.T.P. Pharma Sci., Paris, v. 5, n. 1. p. 83-88, 1995.

GILCHRIST, P. J.; HEBDEN, J. M.; WILSON, C. G.; SPILLER, R.;PERKINS, A. C.; BINNS, J.S. Regional differences in colonic absorption?-A study using the Pulsincap ${ }^{\circledR}$ delivery system. Proceed. Inter, Symp. Control. Rel. Bioact. Mater., Amsterdam, v. 22, p. 206-207, 1995.
GUPTA, V. K.; ASSMUS, M. W.; BECKERT, T. E.; PRICE, J. C. A novel pH- and time-based multi-unit potential colonic drug delivery system. II. Optimization of multiple response variables. Int. J. Pharm., Amsterdam, v. 213, p. 93-102, 2001.

HAEBERLIN, B.; RUBAS, W.; NOLEN III, H. W.; FRIEND, D. R. In vitro Evaluation of Dexamethasone- ${ }^{2}-\mathrm{D}-$ Glucuronide for Colon-Specific Drug Delivery. Pharma. Res., Amsterdam, v. 10, n. 11, p. 1553-1562, 1993.

HARBOE, E.; LARSEN, C.; JOHANSEN, M.; OLESEN, H. P. Macromolecular Prodrugs. XV. Colon-Targeted Delivery - Bioavailability of Naproxen from Orally Administered Dextran-Naproxen Ester Prodrugs Varying in Molecular Size in The Pig. Pharma. Res., Amsterdam, v. 6, n. 11, 1989.

HEALEY, J.N.C. Enteric coatings and delayed release. In: HARDY, J.G.; DAVIS, S.S.; WILSON, C.G., eds. Drug delivery to the gastrointestinal tract. New York: Ellis Horwood Limited, 1989. p.83-96.

HOVGAARD, L.; BRØNDSTED, H. Dextran hydrogels for colon-specific drug delivery. J. Control. Release, Amsterdam, v. 36, p. 159-166, 1995.

HU, Z.; KIMURA, G.; MAWATARI, S.; SHIMOKAWA, T.; YOSHIKAWA, Y.; TAKADA, K. New preparation method of intestinal pressure-controlled colon delivery capsules by coating machine and evaluation in beagle dogs. J. Control. Release, v. 56, p. 293-302, 1998.

HU, Z.; MAWATARI, S.; SHIBATA, N.; TAKADA, K.; YOSHIKAWA, Y.; ARAKAWA, A.; YOSIDA, Y. Application of a biomagnetic measurement system (BMS) to the evaluation of gastrointestinal transit of intestinal pressure-controlled colon delivery capsules (PCDCs) in human subjects. Pharma. Res., Amsterdam, v. 17 , p. $160-167,2000$ b.

HU, Z.; MAWATARI, S.; SHIMOKAWA, T.; KIMURA, G.; YOSHIKAWA, Y.; SHIBATA, N.; TAKADA, K. Colon delivery efficiencies of intestinal pressure-controlled colon delivery capsules prepared by a coating machine in human subjects. J. Pharm. Pharmacol., London, v. 52, p. 1187-1193, 2000a. 
ISHIBASHI, T.; HATANO, H.; KOBAYASHI, M.; MIZOBE, M.; YOSHINO, H. Design and evaluation of a new capsule- type dosage form for colon-targeted delivery of drugs. Int. J. Pharm., Amsterdam, v. 168, p. 31-40, 1998.

ISHIBASHI, T.; HATANO, H.; KOBAYASHI, M.; MIZOBE, M.; YOSHINO, H. In vivo drug release behavior in dogs from a new colon-targeted delivery system. J. Control. Release, Amsterdam, v. 57, p. 45-53, 1999.

KHAN, M. Z. I.; PREBEG, Z.; KURJAKOVIC, N. A pHdependent colon targeted oral drug delivery system using methacrylic acid copolymers I. Manipulation of drug release using Eudragit ${ }^{\mathbb{R}}$ L100-55 and Eudragit ${ }^{\mathbb{B}}$ S100 combinations. J. Control. Release, Amsterdam, v. 58, p. 215-222, 1999.

KIMURA, Y.; MAKITA, Y.; KUMAGAI, T.; YAMANE, H.; KITAO, T.; SASATANI, H.; KIM, S. I. Degradation of azo-containing polyurethane by the action intestinal flora: its mechanism and application as a drug delivery system. Polymer, Amsterdam, v. 33, p. 5294-5299, 1992.

KOPEEK, J. The potential of water-soluble polymeric carriers in targeted and site-specific drug delivery. $J$. Control. Release, Amsterdam, v. 11, p. 279-290, 1990.

KOPEEK, J.; KOPEKOVÁ, P.; BRØNDSTED, H.; RATHI, R.; XIHOVÁ, B.; YEH, P.-Y.; IKESUE, K. Polymers for colon-specific delivery. J. Control. Release, Amsterdam, v. 19, p. 121-130, 1992.

KRISHNAIAH, Y.S.R.; SATYANARAYANA, S.; PRASAD, Y.V.R.; RAO, S.N. Evaluation of guar gum as a compression coat for drug targeting to colon. Int. J. Pharm., Amsterdam, v. 171, p. 137-146, 1998a.

KRISHNAIAH, Y.S.R.; SATYANARAYANA, S.; PRASAD,Y.V.R.; RAO, S.N. Gamma scintigraphic studies on guar gum matrix tablets for colonic drug delivery in healthy human volunteers. J. Control. Release, Amsterdam, v. 55, p. 245-252, 1998 b.

KROGARS, K.; HEINÄMÄKI, J.; VESALAHTI, J.; MARVOLA, M.; ANTIKAINEN, O.; YLIRUUSI, J. Extrusion-spheronization of $\mathrm{pH}$-sensitive polymeric matrix pellets for possible colonic drug delivery. Int. $J$. Pharm., Amsterdam, v. 199, p. 187-194, 2000.
LAMPRECHT, A.; YAMAMOTO, H.; TAKEUCHI, H.; KAWASHIMA, Y. Microsphere design for the colonic delivery of 5-fluorouracil. J. Control. Release, Amsterdam, v. 90, p. 313-322, 2003.

LAMPRECHT, A.; YAMAMOTO, H.; TAKEUCHI, H.; KAWASHIMA, Y. Design of pH-sensitive microspheres for the colonic delivery of the immunosuppressive drug tacrolimus. Eur. J. Pharm. Biopharm., Stuttgart, v. 58, p. 37-43, 2004.

LARSEN, C.; HARBOE, E.; JOHANSEN, M.; OLESEN, H. P. Macromolecular Prodrugs. XVI. Colon-Targeted Delivery - Comparison of the Rate of Release of Naproxen from Dextran Ester Prodrugs in Homogenates of Various Segments of the Pig Gastrointestinal (GI) Tract. Pharma. Res., Amsterdam, v. 6, n. 12, p. 1989.

LEOPOLD, C.S. Coated dosage forms for colon-specific delivery. PSTT, Amsterdam, v.2, n.5, p.197-204, 1999.

LEOPOLD, C. S.; EIKELER, D. Basic coating polymers for colon-specific drug delivery in inflammatory bowel disease. Drug Dev. Ind. Pharm., New York, v. 26, n. 12, p. 1239-1246, 2000.

LIU, L.; FISHAMN, M. L.; KOST, J.; HICKS, K. B. Pectinebased systems for colon-specific drug delivery via oral route. Biomaterials, Amsterdam, v. 24, p. 3333-3343, 2003.

LLOYD, A. W.; HODGES, N. A.; MARTIN, G. P.; SOOZANDEHFAT, S. H. Azo reduction is mediated by enzymatically generated low molecular weight electron carriers. J. Pharma. Pharmacol., London, v.45, p. 21P, 1993.

LUPPI, B.; CERCHIARA, T.; BIGUCCI, F.; ORIENTI, I.; ZECCHI, V. pH-sensitive polymeric physical-mixture for possible site-specific delivery of ibuprofen. Eur. J. Pharm. Biopharm., Suttgart, v. 55, p. 199-202, 2003.

MACLEOD, A. D. Dextran prodrugs for colonic-specific drug delivery. In: FRIEND, D. R. ed. Oral colon-specific drug delivery. London: CRC PRESS, 1992. p.213-232.

MACLEOD, A. D.; TOZER, T. N. Kinetic perspectives in colonic drug delivery. In: FRIEND, D. R. ed. Oral colonspecific drug delivery. London: CRC Press, 1992. p. 85114. 
MACLEOD, A. D.; FRIEND, D. R.; TOZER, T. N. Synthesis and chemical stability of glucocorticoid-dextran esters: potential prodrugs for colon-specific delivery. Int. J. Pharm., Amsterdam, v. 92, p. 105-114, 1993.

MACLEOD, G.S.; FELL, J.T.; COLLETT, J.H.; SHARMA, H.L.; SMITH, A.M. Selective drug delivery to the colon using pectin: chitosan: hydroxypropyl methylcellulose film coated tablets. Int. J. Pharm., Amsterdam, v. 187, p. 251-257, 1999.

MCNEIL, M. E.; STEVENS, H.N.E. Dispensing device. WO 90/09168, 1990.

MILLER, J. A.; MILLER, E. C. The carcinogenicity of 3methoxi-4-aminoazo-benzene and its N-methyl derivatives for extrahepatic tissues of the rat. Cancer Research, Amsterdam, v. 21, p. 1068-1074.

MILOJEVIC, S.; NEWTON, J. M.; CUMMINGS, J. H.; GIBSON, G. R.; BOTHMAN, R. L.; RING, S. G.; ALLWOOD, M. C.; STOCKHAM, M. Amylose, the new perspective in oral drug delivery to the human large intestine. STP Pharma Sci, Paris, v. 5, n. 1, p. 47-53, $1995 a$.

MILOJEVIC, S.; NEWTON, J. M.; CUMMINGS, J. H.; GIBSON, G. R.; BOTHMAN, R. L.; RING, S. G.; STOCKHAM, M.; ALLWOOD, M. C. Amylose as a coating for drug delivery to the colon: Preparation and in vitro evaluation using 5-aminosalicylic acid pellets. $J$. Control. Release, Amsterdam, v. 38, p. 75-84, 1995 b.

MILOJEVIC, S.; NEWTON, J. M.; CUMMINGS, J. H.; GIBSON, G. R.; BOTHMAN, R. L.; RING, S. G.; STOCKHAM, M.; ALLWOOD, M. C. Amylose as a coating for drug delivery to the colon: Preparation and in vitro evaluation using glucose pellets. Int. J. Pharm., Amsterdam, v. 38, p. 85-94, 1995 c.

NYKÄNEN, P.; KROGARS, K.; SÄKKINEN, M.; HEINÄMÄKI, J. JÜRJENSON, H.; VESKI, P.; MARVOLA, M. Organic acids as excipients in matrix granules for colon-specific drug delivery. Int. J. Pharm., Amsterdam, v. 184, p. 251-261, 1999.

NYKÄNEN, P.; LEMPÄÄ, S.; AALTONEN, M.-L.; JÜRJENSON, H.; VESKI, P.; MARVOLA, M. Citric acid as excipient in multiple-unit enteric-coated tablets for targeting drugs on the colon. Int. J. Pharm., Amsterdam, v. 229, p. 115-162, 2001.
PEETERS, R.; KINGET, R. Film-forming polymers for colonic drug delivery: I. Synthesis and physical and chemical properties of methyl derivates of Eudragit S. Int. J. Pharm., Amsterdam, v.94, p. 125-134, 1993.

POZZI, F.; FURLANI, P.; GAZZANIGA, A.; DAVIS, S. S.; WILDING, I.R. The TIME CLOCK ${ }^{\circledR}$ system: a new oral dosage form for fast and complete release of a drug after a predetermined lag time. J. Control. Release, Amsterdam, v. 31, p. 99-108, 1994.

PRASAD,Y.V.R.;KRISHNAIAH,Y.S.R.; SATYANARAYANA, $\mathrm{S}$. In vitro evaluation of goma guar as a carrier for colon-specific drug delivery. J. Control. Release, Amsterdam, v. 51, p. 281287, 1998.

QUADROS, E.; CASSIDY, J.; HIRSCHBERG, Y.; OBERLE, R.; CARR, J.; SAVASTANO, L. Evaluation of a novel colonic delivery device in vivo. S.T.P. Pharma Sci., Paris, v.5, n.1, p. 77-82, 1995.

RUBINSTEIN, A.; NAKAR, D.; SINTOV, A. Chondroitin sulphate: A potential biodegradable carrier for colonspecific drug delivery. Int. J. Pharm., Amsterdam, v. 84, p. 141-150, 1992a.

RUBINSTEIN, A.; NAKAR, D.; SINTOV, A. Colonic drug delivery: Enhanced release of indomethacin from crosslinked chondroitin matrix in rat cecal content. Pharma. Res., Amsterdam, v. 9, n. 2, p. 276-278, 1992 b.

RUBINSTEIN, A; SINTOV, A. Biodegradable polymeric matrices with potential specificity to the large intestine. In: FRIEND, D. R. ed. Oral colon-specific drug delivery, London, CRC Press, 1992. p. 233- 257.

RUBINSTEIN, A.; RADAI, R.; EZRA, M.; PATHAK, S.; ROKEM, S. In vitro evaluation of calcium pectinate: A potential colon-specific drug delivery carrier. Pharma. Res., Amsterdam, v.10. n. 2, p. 258-263, 1993.

RUBINSTEIN, A.; TIROSH, B.; BALUOM, M.; NASSAR, T.; DAVID, A.; RADAI, R.; GLIKO-KABIR, I.; FRIEDMAN, M. The rationale for peptide drug delivery to the colon and the potential of polymeric carriers as effective tools. J. Control. Release, Amsterdam, v. 46, p. 59-73, 1997. 
RUDOLPH, M.W.; KLEIN, S.; BECKERT, T.E.; PETEREIT, H. U.; DRESSMAN, J. B. A new 5aminosalicylic acid multi-unit dosage for the therapy of ulcerative colitis. Eur. J. Pharm. Biopharm., Stuttgart, v.51, p. 183-190, 2001.

SCHACHT, E.; GEVAERT, A.; KENAWY, E. R.; MOLLY, K.; VERSTRAETE, W.; ADRIAENSENS, P.; CARLEER,R.; GELAN, J. Polymers for colon specific drug delivery. J. Control. Release, Amsterdam, v. 39, p. 327-338, 1996.

SCHRÖDER, H.; LEWKONIA, R.M.; PRICE-EVANS, D.A. Metabolism of salicylazosulfapyridine in healthy subjects and patients with ulcerative colitis. Clin. Pharmacol. Ther., London, v. 14, p. 802-809, 1973.

SEMDÉ, R.; AMIGHI, K.; DEVLEESCHOUWER, M. J.; MOœ, A.J. Studies of pectin HM/ EUDRAGIT ${ }^{\circledR}$ RL/ EUDRAGIT ${ }^{\circledR} \mathrm{NE}$ film-coating formulations intended for colonic drug delivery. Int. J. Pharm., Amsterdam, v. 197, p. 182-192, 2000a.

SEMDÉ, R.; AMIGHI, K.; DEVLEESCHOUWER, M. J.; MOœ, A.J. Effect of pectinolytic enzymes on the theophylline release from pellets coated with water insoluble polymers containing pectin HM or calcium pectinate. Int. J. Pharm., Amsterdam, v. 197, p. 169-179, $2000 \mathrm{~b}$.

SHIBATA, N.; OBNO, T.; SHIMOKAWA, T.; HU, Z.;YOSHIKAWA, Y.; KOGA, K.; MURAKAMI, M.; TAKADA, K. Application of pressure-controlled colon delivery capsule to oral administration of glycyrrhizin in dogs. J. Pharma. Pharmacol., London, v.53, p. 441-447, 2001.

SIEW, L. F.; MAN, S-T.: NEWTON, J. M.; BASIT, A.W. Amylose formulations for drug delivery to the colon: a comparison of two fermentation models to assess colonic targeting performance in vitro. Int. J. Pharm., Amsterdam, v. 273, p. 129-134, 2004.

SIMOMSEN, L.; HOVGAARD,L.; MORTENSEN, P. B.; BRØNDSTED, H. Dextran hydrogels for colon-specific drug delivery. V. Degradation in human intestinal incubation models. Eur. J. Pharm. Biopharm., v. 3, p. 329-337, 1995.
SRIAMORNSAK, P.; PRAKONGPAN, S.; PUTTIPIPATKHACHORN, S.; KENNEDY, R. A. Development of sustained release theophylline pellets coated with calcium pectinate. Int. J. Pharm., Amsterdam, v. 47, p. 221-232, 1997.

STEED, K. P.; HOOPER, G.; MONTI, N.; BENEDETTI, M. S.; FORNASINI, G.; WILDING, I. R. The use of pharmacoscintigraphy to focus the development strategy for a novel 5-ASA colon targeting system ("TIMECLOCK ${ }^{\circledR}$ "system). J. Control. Release, Amsterdam, v.49, p. 115-122, 1997.

TAKAYA, T.; IKEDA, C.; IMAGAWA, N.; NIWA, K.; TAKADA, K. Development of a colon delivery capsule and the pharmacological activity of recombinant human granulocyte colony-stimulating factor (rhG-CSF) in beagles dogs. J. Pharm. Pharmacol., London, v. 47, p. 474-478, 1995.

TAKEMURA, S.; WATANABE, S.; KATSUMA, M.; FUKUI, M. Human gastrointestinal transit study of a novel colon delivery system (CODES ${ }^{\mathrm{TM}}$ ) using ${ }^{3-}$ scintigraphy. Proceed. Inter, Symp. Control. Rel. Bioact. Mater., v. 27, p. 2000.

THEEUWES, F.; WONG, P. L.; BURKOTH, T. L.; FOX, D. A. Osmotic Systems for Colon-Targeted Drug Delivery. . In: BIECK, P. R., ed. Colonic drug absorption and metabolism, Drugs and the Pharmaceutical Sciences, New York: Marcel-Dekker, v. 60, 1993, p. 137-158.

TURKOGLU, M.; UGURLU, T. In vitro evaluation of pectin-HPMC compression coated 5-aminosalicylic acid tablets for colonic delivery. Eur. J. Pharm. Biopharm., Stuttgart, v. 53, p. 65-73, 2002.

VAN DER MOOTER, G.; SAMYN, C.; KINGET, R. Azo polymers for colon-specific drug delivery. Int. J. Pharm., Amsterdam, v. 87, p. 37-46, 1992.

VAN DER MOOTER, G.; SAMYN, C.; KINGET. R. Azo polymers for colon-specific drug delivery. II: Influence of the type of azo polymers on the degradation by intestinal microflora. Int. J. Pharm., Amsterdam, v. 97, p. 133-139, 1993.

VAN DER MOOTER, G.; OFFRINGA, M.; KALALA, W.; SAMYN, C.; KINGET, R. Synthesis and evaluation of new linear azo-polymers for colonic-targeting. S.T.P. Pharma Sci., Paris, v. 5, n. 1, p. 36-40, 1995. 
VAN DER MOOTER, G.; KINGET, R. Oral colon-specific drug delivery. A Review. Drug delivery, Amsterdam, v. 2, p. 81-93, 1995a.

VAN DER MOOTER, G.; SAMYN, C.; KINGET. In vivo evaluation of a colonic-specific drug delivery system: an absorption study of theophylline from capsules coated with azo polymers in rats. Pharm. Res., Amsterdam, v. 12, n. 2 , p. 244-247, 1995b.

VERMA, R. K.; KRISHNA, D. M.; GARG, S. Formulation aspects in the development of osmotically controlled oral drug delivery systems. J. Control. Release, Amsterdam, v.79, p. 7-27, 2002.

VERVOORT, L.; KINGET, R. In vitro degradation by colonic bacteria of inulinHP incorporated in Eudragit RS films. Int. J. Pharm., Amsterdam, v. 129, p. 185-190, 1996.

VERVOORT, L.; ROMBAUT, P.; VAN DER MOOTER, G.; AUGUSTIJNS, P.; KINGET, R. Inulin hydrogels. II. In vitro degradation study. Int. J. Pharm., Amsterdam, v. 172, p. 137-145, 1998a.

VERVOORT, L.; VAN DER MOOTER, G.; AUGUSTIJNS, P.; KINGET, R. Inulin hydrogels. I. Dynamic and equilibrium swelling properties. Int. J. Pharm., Amsterdam, v. 172, p. 127-135, 1998 b.

WATANABE, S.; KAWAI, H.; KATSUMA, M.; FUKUI, M.; Colon specific drug release system. US patent application (09/183,339), 1998.

WATTS, P. J.; ILLUM, L. Colonic drug delivery. Drug Dev. Ind. Pharm., London, v. 23, p. 893-913, 1997.

WILDING, I. R.; DAVIS, S. S.; POZZI, F.; FURLANI, P. GAZZANIGA, A. Enteric coated time release systems for colonic targeting. Int. J. Pharm., Amsterdam, v. 111, p. 99-102, 1994.
WILDING, I. R. Scintigraphic evaluation of colonic delivery systems. S.T.P. Pharma Sci., Paris, v.5, n. 1, p. 13-18, 1995.

WILDING, I. R.; BEHRENS, C.; TARDIF, S. J.; WRAY, H.; BIAS, P.; ALBRECHT, W. Combined scintigraphy and pharmacokinetic investigation of enteric-coated mesalazine micropellets in healthy subjects. Aliment. Pharmacol. Ther., London, v. 17, p. 1153-1162, 2003.

YANG, L.; CHU, J. S.; FIX, J. A. ; Colon-specific drug delivery: new approaches and in vitro/ in vivo evaluation, Int. J. Pharm., Amsterdam, v. 235, p. 1-15, 2002.

YANO, H.; HIRAYAMA, F.; KAMADA, M.; ARIMA, H.; UEKAMA, K. Colon-specific delivery of prednisoloneappended \pm -cyclodextrin conjugate: alleviation of systemic side effect after oral administration. J. Control. Release, Amsterdam, v. 79, p. 103-112, 2002.

ZHANG, H.; ALSARRA, I. A.; NEAU, S,H. An in vitro evaluation of chitosan-containing multiparticulate system for macromolecule delivery to the colon. Int. J. Pharm., Amsterdam, v. 239, p. 197-205, 2002.

ZEITON, P.; BRISARD, P. Im Colon zerfallende Tabletten und Irhe Herstellung. Patent Roussel-uclaf, patentschrift DE 3046559 C2, 1988.

ZOU, M.; OKAMOTO, H.; CHENG, G.; HAO, X.; SUN, J.; CUI, F.; DANJO, K. Synthesis and properties of polysaccharide prodrugs of 5-aminosalicylic acid as potential colon-specific delivery systems. Eur. J. Pharm. Biopharm., Stuttgart, p. 1-6, 2004.

Recebido para publicação em 10 de março de 2005. Aceito para publicação em 17 de abril de 2006. 